\title{
50 ANOS DO PPGCI IBICT: ANÁLISE TEXTUAL DA PRODUÇÃO CIENTÍFICA COM IRAMUTEQ
}

\author{
50 YEARS OF PPGCI IBICT: TEXTUAL ANALYSIS OF \\ THE SCIENTIFIC PRODUCTION THROUGH IRAMUTEQ
}

\author{
Rosali Fernandez de Souzaa \\ Priscila Ramos Carvalhob \\ Marcos Gonçalves Ramosc
}

\begin{abstract}
RESUMO
Introdução: Análise textual da produção científica dos 50 anos do Programa de PósGraduação em Ciência da Informação do Instituto Brasileiro de Informação em Ciência e Tecnologia. Objetivo: Identificar os temas trabalhados nas pesquisas acadêmicas realizadas no programa de pós-graduação durante os seus 50 anos, em virtude da sua representatividade como primeiro curso de mestrado em Ciência da Informação no Brasil. Metodologia: Pesquisa empírica a partir da coleta de dados de dissertações e teses, em reportórios institucionais (CAPES, BDTD, RIDI, Pantheon e RIUFF), para análise textual através do programa IRaMuTeQ e discussão com base na revisão bibliográfica e documental. Resultados: Foram analisados 752 títulos e 454 resumos de teses (169) e dissertações (583) que apresentaram como principais abordagens temáticas: usos e efeitos da informação;metrias da informação; estudos sobre instituições sediadas no Rio de Janeiro; perspectivas teóricas e conceituais na Ciência da Informação. Conclusões: O estudo espera contribuir para o conhecimento histórico da Ciência da Informação no Brasil.
\end{abstract}

Descritores: Ciência da Informação. Produção científica. Pós-graduação. Ibict, IRaMuTeQ.

\section{INTRODUÇÃO}

No cerne de uma nova problemática informacional devido ao final da

\footnotetext{
a Doutorado realizado na Polytechnic of North London, conferido pelo Council for National Academic Awards. Pesquisadora do Instituto Brasileiro de Informação em Ciência e Tecnologia - IBICT / MCTI. Docente do Programa de Pós-Graduação em Ciência da Informação da Universidade Federal do Rio de Janeiro (IBICT- UFRJ). E-mail: rosali@ibict.br

b Doutoranda do Programa de Pós-Graduação em Ciência da Informação da Universidade Federal do Rio de Janeiro (IBICT- UFRJ). E-mail: carvalho.priscila@gmail.com

c Doutorando do Programa de Pós-Graduação em Ciência da Informação da Universidade Federal do Rio de Janeiro (IBICT- UFRJ).E-mail: marcosgon54@hotmail.com
} 
Segunda Guerra Mundial (1939-1945) e início da Guerra Fria (1947-1991), período de disputa geopolítica entre Estados Unidos (EUA) e União Soviética,despontou a necessidade de uma nova ciência.Neste cenário de competição pelo desenvolvimento científico e tecnológico, a informação ganhou importância, tendo como marco a publicação As we may think (Como nós pensamos) de Vannevar Bush em 1945, que apontou o problema da "explosão informacional, isto é, o crescimento do número de documentos, e a dificuldade resultante disso de recuperação da informação", assim como uma possível solução através da automação dos processos de recuperação (ARAUJO, 2018, p.17).

No início da institucionalização da Ciência da Informação é perceptível o foco na informação advinda de ciência e tecnologia, bem como a ampliação de seu escopo de estudo apenas da posse de documentos para também os fluxos e processamentos da informação, assim como sua materialização em diferentes produtos e serviços (ARAUJO, 2018, p.16).

$\mathrm{Na}$ década de 60, após muitas discussões o conceito de Ciência da Informação emergiu sintetizado por Borko (1968):

Ciência da Informação é a disciplina que investiga as propriedades e o comportamento informacional, as forças que governam os fluxos de informação, e os significados do processamento da informação, visando à acessibilidade e a usabilidade ótima. A Ciência da Informação está preocupada com o corpo de conhecimentos relacionados à origem, coleção, organização, armazenamento, recuperação, interpretação, transmissão, transformação, e utilização da informação. [...] Têm ambos componentes, de ciência pura visto que investiga seu objeto sem considerar sua aplicação, e um componente de ciência aplicada, visto que desenvolve serviços e produtos (BORKO, 1968, p.1-2).

A fundamentação epistemológica da Ciência da Informação teve diversas fontes e autores, entre eles: Samuel Clement Bradford, (1878-1948); Suzanne Briet (1894-1989); Paul Otlet (1868-1944); S. R. Ranganathan (1892- 1972); Jesse H. Shera (1903-1982), Vannevar Bush (1890-1974), Robert Escarpit (1918-2000), Jean Meyriat (1921-2010) e Yves Jeanneret (1951-2020) indicar nas referências.

Para Saracevic (1996), a Ciência da Informação tem relações interdisciplinares com quatro campos: Biblioteconomia, Ciência da Computação, 
Ciência Cognitiva e Comunicação. A relação com a Biblioteconomia reside no compartilhamento de seu papel social e na preocupação comum com os registros gráficos. Com a Ciência da Computação é baseada na aplicação da computação na recuperação da informação, bem como nos produtos, serviços e redes associados. Com a Ciência Cognitiva compartilha interesses comuns em questões e soluções de Inteligência Artificial para os sistemas de informação. Com a Comunicação divide o olhar e estudo sobre o fenômeno e o processo informação e comunicação. (SARACEVIC, 1996).

No Brasil, o desenvolvimento da Ciência da Informação ocorreu a partir do estabelecimento de cursos de pós-graduação, por meio das linhas de pesquisa que expressam determinada produção de conhecimento em uma área de concentração, sustentada pelos docentes e pesquisados do programa. Outro fator importante na ampliação do campo foram os grupos de pesquisa envolvendo pesquisadores, docentes e discentes com o objetivo de ampliar a pesquisa e a produção científica.

Nesse sentido, é imprescindível relatar a trajetória do primeiro curso de mestrado em Ciência da Informação,do Instituto Brasileiro de Informação em Ciência e Tecnologia (IBICT), precursor no Brasil, que de acordo com Pinheiro \& Loureiro (1995) passou por três fases até sua consolidação no Brasil: $1^{\underline{a}}$ fase de implantação, de 1970 até $1982 ; 2^{\text {a }}$ fase de transição, de 1983 até 1986; e $3^{\text {a }}$ fase de consolidação a partir de 1987 (PINHEIRO; LOUREIRO, 1995, p.11).

O Programa de Pós-Graduação em Ciência da Informação (PPGCI) do IBICT faz 50 anos de criação em 2020, o que despertou a curiosidade sobre os temas pesquisados pelos discentes, nos âmbitos do mestrado e do doutorado, com orientação de corpo docente, ao longo do respectivo período.

Para tanto, este artigo se propõe identificar os principais temas abordados pelas pesquisas acadêmicas realizadas nos 50 anos do Programa de PósGraduação em Ciência da Informação do Instituto Brasileiro de Informação em Ciência e Tecnologia, a partir da análise de conteúdo de resumos e títulos das teses e dissertações, coletadas em repositórios institucionais, através do programa de código aberto e gratuito IRaMuTeQ. 


\section{PRIMEIRO PROGRAMA DE CIÊNCIA DA INFORMAÇÃO NO BRASIL}

O IBICT1lançou o primeiro curso de mestrado em Ciência na Informação em 1970, assim introduzindo o campo do conhecimento no Brasil e na América Latina, por meio de convênio acadêmico com a Universidade Federal do Rio de Janeiro (UFRJ) e 1994, o programa passou a ter também o doutorado. Além disso, o PPGCI mudou em 2003 para Universidade Federal Fluminense (UFF), onde perdurou até 2008, retornando o convênio com a UFRJ no final de 2008.

O PPGCI foi desenvolvido pelo IBICT a partir de sua experiência de 35 anos com o Curso de Documentação Científica, no nível de especialização, criado em 1955. Porém, o grande diferencial e pioneirismo do PPGCl foi trazer professores estrangeiros de expressão internacional originários da Ciência da Informação para formação do corpo docente, tais como: Tefko Saracevic, Frederick Wilfrid Lancaster, Bert Roy Boyce, Jack Mills, Derek Langridge, Ingetraut Dahlberg, LaVahn Marie Overmyer,Suman Datta, Douglas Foskett, John Joseph Eyre, James Whitney Perry e Jessica Perry. Ademais, alguns professores foram orientadores das primeiras dissertações de mestrado até 1981 como, por exemplo: Lancaster com 34 orientações, Saracevic com 13, Overmyer com 3, Mills com 2, Boyce com 2e Foskett com1(PINHEIRO, LOUREIRO, 1995, p.12). Portanto, é fundamental mencionarmos as origens acadêmicas destes docentes estrangeiros, visto que estes influenciaram os primórdios da pesquisa científica em Ciência da Informação no Brasil, conforme Quadro 1.

\section{Quadro 1 - Formação dos Docentes Estrangeiros do PPGCI}

\begin{tabular}{|l|l|}
\hline \multicolumn{1}{|c|}{ Docente } & \multicolumn{1}{c|}{ Breve Currículo } \\
\hline $\begin{array}{l}\text { Tefko } \\
\text { Saracevic }\end{array}$ & $\begin{array}{l}\text { Croata, radicado nos EUA, formado em Engenheira Elétrica com mestrado e } \\
\text { doutorado em Ciência da Informação, professor da Case Western Reserve } \\
\text { University (EUA). Pesquisador de bibliotecas digitais, sistema de recuperação } \\
\text { de informação com destaque sobre a relevância. }\end{array}$ \\
\hline $\begin{array}{l}\text { Frederick } \\
\text { Wilfrid } \\
\text { Lancaster }\end{array}$ & $\begin{array}{l}\text { Britânico, radicado nos EUA, formado em Biblioteconomia e Ciência da } \\
\text { Informação, professor da University of Illinois (EUA). Pesquisador da } \\
\text { recuperação da informação com ênfase na indexação. }\end{array}$ \\
\hline
\end{tabular}

\footnotetext{
${ }^{1}$ Acompanhando as transformações do CNPq (Conselho Nacional de Pesquisas) e da pesquisa brasileira e o movimento disciplinar da informação cientifica e tecnológica em âmbito mundial, o IBBD (Instituto Brasileiro de Bibliografia e Documentação) tem o seu nome alterado para IBICT em 1976. (MARTELETO, 2009).
} 


\begin{tabular}{|c|c|}
\hline $\begin{array}{l}\text { Bert Roy } \\
\text { Boyce }\end{array}$ & $\begin{array}{l}\text { Americano formado em História com mestrado em Ciências e doutorado em } \\
\text { Filosofia. Professor na University of Missouri (EUA) e na Louisiana State } \\
\text { University (EUA). Pesquisador da mediação na Ciência da Informação. }\end{array}$ \\
\hline Jack Mills & $\begin{array}{l}\text { Britânico formado em Biblioteconomia, professor da Polytechnic of North } \\
\text { London, School of Librarianship(Reino Unido), e pesquisador do } \\
\text { desenvolvimento de classificaçãoe recuperação da informação. Mentor e } \\
\text { revisor da Classificação Bibliográfica de Bliss. Membro do Classification } \\
\text { Research Group (CRG). }\end{array}$ \\
\hline $\begin{array}{l}\text { Derek } \\
\text { Langridge }\end{array}$ & $\begin{array}{l}\text { Britânico formado emLetras, professor da Polytechnic of North London, } \\
\text { School of Librarianship(Reino Unido), e pesquisador da classificação, } \\
\text { indexação e organização do conhecimento. Membro do Classification } \\
\text { Research Group (CRG). }\end{array}$ \\
\hline $\begin{array}{l}\text { Ingetraut } \\
\text { Dahlberg }\end{array}$ & $\begin{array}{l}\text { Alemã formada em Documentação com doutorado em Filosofia com foco na } \\
\text { Linguística e História da Ciência, professora na Johannes Gutenberg } \\
\text { University Mainz (Alemanha). Pesquisadora da organização do conhecimento } \\
\text { e desenvolveu a teoria do conceito. }\end{array}$ \\
\hline $\begin{array}{l}\text { LaVahn } \\
\text { Marie } \\
\text { Overmyer }\end{array}$ & $\begin{array}{l}\text { Americana formação em Biblioteconomia, professora da Case Western } \\
\text { Reserve University (EUA) e pesquisadora do uso das bibliotecas como um } \\
\text { sistema de informação. }\end{array}$ \\
\hline $\begin{array}{l}\text { Suman } \\
\text { Datta }\end{array}$ & $\begin{array}{l}\text { Indianaformada em Biblioteconomia, professora da Polytechnic of North } \\
\text { London, School of Librarianship (Reino Unido), pesquisadora de classificação } \\
\text { bibliográfica,sistemas de classificação, recuperação de informações e } \\
\text { armazenamento. }\end{array}$ \\
\hline $\begin{array}{l}\text { Douglas } \\
\text { John Foskett }\end{array}$ & $\begin{array}{l}\text { Britânico com formação emBiblioteconomia (mestre e doutor), professor da } \\
\text { University of London (Reino Unido), pesquisador da classificação e } \\
\text { indexação. Fez parte dos membros fundadores do Classification Research } \\
\text { Group (CRG) e desenvolveu o esquema London Education Classification } \\
\text { para organização de coleções de bibliotecas. }\end{array}$ \\
\hline $\begin{array}{l}\text { John Joseph } \\
\text { Eyre }\end{array}$ & $\begin{array}{l}\text { Britânico, professor da Polytechnic of North London,School of Librarianship } \\
\text { (Reino Unido) e cientista da informação. Pesquisador de sistemas de } \\
\text { informação e automação de bibliotecas. }\end{array}$ \\
\hline $\begin{array}{l}\text { James } \\
\text { Whitney } \\
\text { Perry }\end{array}$ & $\begin{array}{l}\text { Americano formado em química e mestre em Ciências, professor da } \\
\text { University of Arizona (EUA). Vanguardista no uso de computadores para } \\
\text { indexação, classificação e pesquisa de documentos. }\end{array}$ \\
\hline $\begin{array}{l}\text { Jessica } \\
\text { Perry }\end{array}$ & $\begin{array}{l}\text { Americana professora da University of Arizona (EUA) e pesquisadora da } \\
\text { indexação, classificação, redes de informação, processamento da } \\
\text { informação, recuperação da informação, lexicografia, linguística, thesaurus, } \\
\text { vocabulário e índice de assuntos/termos (LINCS Project Document Series). }\end{array}$ \\
\hline
\end{tabular}

Fonte: criação dos autores com base em Gomes (1974)

Convém contextualizar que o PPGCI IBICT foi lançado,durante o regime militar no Brasil (1964-1985)², na década de 70, quando surgiram os primeiros microprocessadores (1971); começaram a produção de fibras ópticas em cabos para transmissão de dados (1972) e, em seguida, desenvolveram os primeiros microcomputadores ou computadores pessoais (1978). Nesse momento, também estava em ebulição a necessidade de sistemas de informação para lidar com volume, velocidade e variedade de fontes, como também a classificação, o

\footnotetext{
2 Década de 70. Disponível em: https://www2.camara.leg.br/atividade-legislativa/plenario/ discursos/escrevendohistoria/visitantes/panorama-das-decadas/copy_of_decada-de-70. Acesso em: 20 jun. 2020.
} 
armazenamento e a recuperação de informações para governos, instituições, universidades e empresas (indústria).

O clima genuíno da informação como ciência contribuiu para que algumas abordagens teóricas ganhassem interesse mundial como, por exemplo, a indexação e a classificação de Ranganathan (Classificação de Dois Pontos Colon Classification - e análises de facetas), Mills (teoria da classificação), Cleverdon (experimentos de Cranfield), Farradane (indexação relacional), Coates (esquema facetado do BTI - British Technology Index), Austin (sistema de indexação Precis - Preserved Context Index System da BNB - British National Bibliography), Needham (organização do conhecimento), Garfield e de Solla Price (Bibliometria) e Salton (recuperação de informações). (EYRE, 1995, p.3).

Nessa perspectiva, o programa começa voltado para o processamento técnico da informação com foco nas atividades de planejamento de sistemas e processamento da informação, distribuídas em uma grade formada por cinco disciplinas obrigatórias:1)organização de serviços de informação; 2) catalogação avançada; 3) sistemas de classificação; 4) técnicas de indexação e resumo; 5) processamento de dados na documentação; e mais sete disciplinas optativas: programação, epistemologia, didática, linguística, teoria da comunicação, teoria dos conjuntos, e metodologia da pesquisa(PINHEIRO; LOUREIRO, 1995, p.12), exibidas no Quadro 2.

Quadro 2 - Primeiras Áreas de Concentração e Disciplinas do PPGCI

\begin{tabular}{|c|c|c|c|}
\hline $\begin{array}{c}\text { Áreas de } \\
\text { Concentração }\end{array}$ & Disciplinas & Teórico & Prático \\
\hline \multirow{12}{*}{$\begin{array}{l}\text { 1. Usuários; } \\
\text { 2. Administração de } \\
\text { sistemas de } \\
\text { informação/ } \\
\text { documentação; } \\
\text { 3. Transferência da } \\
\text { informação (ênfase na } \\
\text { matemática e } \\
\text { estatística). }\end{array}$} & Organização e serviços de informação & $\mathrm{X}$ & $\mathrm{X}$ \\
\hline & $\begin{array}{l}\text { Catalogação avançada (Automação de } \\
\text { bibliotecas) }\end{array}$ & & $\mathrm{X}$ \\
\hline & $\begin{array}{l}\text { Sistemas de classificação (Teoria da } \\
\text { classificação) }\end{array}$ & $\mathrm{X}$ & \\
\hline & Técnicas de indexação e resumo & & $\mathrm{X}$ \\
\hline & Processamento de dados na documentação & & $\mathrm{X}$ \\
\hline & Programação & & $\mathrm{X}$ \\
\hline & Epistemologia & $\mathrm{X}$ & \\
\hline & Didática & $\mathrm{X}$ & $\mathrm{X}$ \\
\hline & Linguística & $\mathrm{X}$ & \\
\hline & Teoria da comunicação & $\mathrm{X}$ & \\
\hline & Teoria dos conjuntos & $\mathrm{X}$ & \\
\hline & Metodologia de pesquisa & $\mathrm{X}$ & \\
\hline
\end{tabular}

Fonte: criação dos autores com base em Gomes (1974); Carvalho (1978);

Pinheiro \& Loureiro (1995) 
A primeira turma formada por profissionais e professores da área de Biblioteconomia e Documentação de diversas partes do país, transmitiram conhecimentos aos demais profissionais responsáveis pelas bibliotecas e sistemas de informação no país. Em 1972, ainda sem o curso de doutorado no país, para dar continuidade a pesquisa na área, muitos discentes tiveram que realizar os estudos em universidades estrangeiras. Nesse sentido, o PPGCI contribuiu para o desenvolvimento da pesquisa acadêmica da Ciência da Informação no Brasil através da formação de profissionais especializados e capacitados que atuaram como colaboradores no seu próprio quadro, assim como para composição do quadro docente de novos programas de pósgraduação na respectiva área, conforme Quadro 3.

Quadro 3 - Origem dos Discentes das Primeiras Dissertações - 1972

\begin{tabular}{|c|c|c|c|}
\hline Discente & Origem & Título & Orientador \\
\hline $\begin{array}{l}\text { Jandira } \\
\text { Batista de } \\
\text { Assunção }\end{array}$ & $\begin{array}{l}\text { Professora Assistente da Escola de } \\
\text { Biblioteconomia e Bibliotecária do } \\
\text { Instituto de Ciências Biológicas da } \\
\text { Universidade Federal de Minas } \\
\text { Gerais. }\end{array}$ & $\begin{array}{l}\text { Projeto de um sistema de } \\
\text { classificação bibliográfica } \\
\text { analítico-sintético (ou } \\
\text { facetado) para a indexação } \\
\text { e recuperação de } \\
\text { informações em Biologia. }\end{array}$ & $\begin{array}{l}\text { Douglas } \\
\text { John } \\
\text { Foskett; } \\
\text { Jack Mills }\end{array}$ \\
\hline $\begin{array}{l}\text { Malvina } \\
\text { Vianna } \\
\text { Rosa }\end{array}$ & $\begin{array}{l}\text { Bibliotecária-Chefe da Faculdade de } \\
\text { Odontologia da Universidade } \\
\text { Federal do Rio Grande do Sul, } \\
\text { desde } 1960 .\end{array}$ & $\begin{array}{l}\text { Classificação facetada em } \\
\text { Odontologia. }\end{array}$ & Jack Mills \\
\hline $\begin{array}{l}\text { Laura } \\
\text { Maia de } \\
\text { Figueiredo }\end{array}$ & $\begin{array}{l}\text { Diretora Agregada do Instituto } \\
\text { Brasileiro de Bibliografia e } \\
\text { Documentação. }\end{array}$ & $\begin{array}{l}\text { Distribuição da literatura } \\
\text { geológica brasileira: estudo } \\
\text { bibliométrico. }\end{array}$ & $\begin{array}{l}\text { Tefko } \\
\text { Saracevic }\end{array}$ \\
\hline $\begin{array}{l}\text { Alice } \\
\text { Barros } \\
\text { Maia }\end{array}$ & $\begin{array}{l}\text { Bibliotecária-Chefe da Seção de } \\
\text { Ciências Sociais do Serviço de } \\
\text { Bibliografia do Instituto Brasileiro de } \\
\text { Bibliografia e Documentação. }\end{array}$ & $\begin{array}{l}\text { Centro de análise da } \\
\text { informação: requisitos } \\
\text { mínimos para o seu } \\
\text { funcionamento. }\end{array}$ & $\begin{array}{l}\text { Celia } \\
\text { Ribeiro } \\
\text { Zaher }\end{array}$ \\
\hline $\begin{array}{l}\text { Alice } \\
\text { Príncipe } \\
\text { Barbosa }\end{array}$ & $\begin{array}{l}\text { Diretora do Serviço de Intercâmbio } \\
\text { de Catalogação e Professora de } \\
\text { Teoria da Classificação do Curso de } \\
\text { Documentação Científica do IBBD e } \\
\text { de Catalogação e Classificação da } \\
\text { Escola de Biblioteconomia e } \\
\text { Documentação da FEFIEG. }\end{array}$ & $\begin{array}{l}\text { Projeto CALCO: adaptação } \\
\text { do MARC II para } \\
\text { implantação de uma } \\
\text { central de processamento } \\
\text { da catalogação } \\
\text { cooperativa. }\end{array}$ & $\begin{array}{l}\text { LaVahn } \\
\text { Marie } \\
\text { Overmyer }\end{array}$ \\
\hline $\begin{array}{l}\text { Perola } \\
\text { Cardoso } \\
\text { Raulino }\end{array}$ & $\begin{array}{l}\text { Chefe da Seção de Classificação e } \\
\text { Catalogação da Biblioteca do } \\
\text { Senado Federal e Professora do } \\
\text { Departamento de Biblioteconomia } \\
\text { da Faculdade de Estudos Sociais } \\
\text { Aplicados da UnB. }\end{array}$ & $\begin{array}{l}\text { Um sistema de } \\
\text { disseminação seletiva da } \\
\text { informação para os } \\
\text { membros do Congresso } \\
\text { Nacional. }\end{array}$ & \begin{tabular}{|l} 
Astério \\
Tavares
\end{tabular} \\
\hline $\begin{array}{l}\text { Adda } \\
\text { Drugg de } \\
\text { Freitas }\end{array}$ & $\begin{array}{l}\text { Diretora da Biblioteca Pública do } \\
\text { Estado do Rio Grande do Sul. }\end{array}$ & $\begin{array}{l}\text { Processamento de } \\
\text { informações de registros } \\
\text { médico-hospitalares. }\end{array}$ & $\begin{array}{l}\text { Clovis } \\
\text { Francisconi; }\end{array}$ \\
\hline
\end{tabular}




\begin{tabular}{|c|c|c|c|}
\hline & & & $\begin{array}{l}\text { Paulo } \\
\text { Roberto }\end{array}$ \\
\hline $\begin{array}{l}\text { Hagar } \\
\text { Espanha } \\
\text { Gomes }\end{array}$ & $\begin{array}{l}\text { Diretora do Instituto de Artes e } \\
\text { Comunicação Social da } \\
\text { Universidade Federal Fluminense, } \\
\text { desde 1968; Professora de } \\
\text { Bibliografia e Referência e } \\
\text { Documentação na Universidade } \\
\text { Federal Fluminense e de Técnica de } \\
\text { Pesquisa Documentária do Curso } \\
\text { de Documentação Científica do } \\
\text { IBBD. }\end{array}$ & $\begin{array}{l}\text { Utilização do Sistema de } \\
\text { DSI do Technical } \\
\text { Information Service of } \\
\text { National Resarch Council } \\
\text { from Canadá: algumas } \\
\text { implicações. }\end{array}$ & $\begin{array}{l}\text { Celia } \\
\text { Ribeiro } \\
\text { Zaher }\end{array}$ \\
\hline $\begin{array}{l}\text { Gilda } \\
\text { Maria } \\
\text { Braga }\end{array}$ & $\begin{array}{l}\text { Bibliotecária-Chefe da Seção de } \\
\text { Pesquisas Bibliográficas e } \\
\text { Traduções do Serviço de } \\
\text { Informações Técnico Científicas do } \\
\text { IBBD e Professora Assistente de } \\
\text { Bibliografia da Escola de } \\
\text { Biblioteconomia e Documentação da } \\
\text { FEFIEG. }\end{array}$ & $\begin{array}{l}\text { Relações Bibliométricas } \\
\text { entre a frente de pesquisa } \\
\text { (research front) e revisões } \\
\text { da literatura: estudo } \\
\text { aplicado à Ciência da } \\
\text { Informação. }\end{array}$ & \begin{tabular}{|l} 
Tefko \\
Saracevic
\end{tabular} \\
\hline $\begin{array}{l}\text { Jerusa } \\
\text { Borges } \\
\text { Gonçalves }\end{array}$ & $\begin{array}{l}\text { Técnica de Documentação da } \\
\text { Escola Interamericana de } \\
\text { Administração Pública da Fundação } \\
\text { Getúlio Vargas. }\end{array}$ & $\begin{array}{l}\text { CICS: Centro de } \\
\text { Informação em Ciências } \\
\text { Sociais - FGV. }\end{array}$ & $\begin{array}{l}\text { Celia } \\
\text { Ribeiro } \\
\text { Zaher }\end{array}$ \\
\hline
\end{tabular}

Fonte: criação dos autores com base em Relatório da Revista Ciência da Informação e IBBD

Nessa linha, pode-se inferir que o PPGCI tem sido desde os primórdios um núcleo difusor de profissionais no campo da Ciência da Informação,e contribuiu para formação do quadro de docentes dos cursos de pós-graduação no Brasil e, em particular, no Estado do Rio de Janeiro. Ademais, o programa foi referência para outros cursos de pós-graduação, tendo o segundo curso de mestrado na Ciência da Informação sido aberto na Universidade de São Paulo (USP) e, na sequência, em 1976, o terceiro curso de mestrado Universidade Federal de Minas Gerais (UFMG), conforme histórico de lançamento dos cursos no Quadro 4.

\section{Quadro 4-Programas de Pós-Graduação em Ciência da Informação no Brasil}

\begin{tabular}{|c|l|c|c|l|l|}
\hline $\mathbf{N}^{\circ}$ & \multicolumn{1}{|c|}{ Instituição } & UF & Ano & \multicolumn{1}{|c|}{ Curso } & \multicolumn{1}{|c|}{ Nível } \\
\hline 1 & $\begin{array}{l}\text { Universidade Federal do Rio de } \\
\text { Janeiro (UFRJ) }\end{array}$ & RJ & 1970 & $\begin{array}{l}\text { Ciência da } \\
\text { Informação }\end{array}$ & $\begin{array}{l}\text { Mestrado e } \\
\text { Doutorado }\end{array}$ \\
\hline 2 & Universidade de São Paulo (USP) & SP & 1972 & $\begin{array}{l}\text { Ciência da } \\
\text { Informação/ } \\
\text { Gestão da } \\
\text { Informação }\end{array}$ & $\begin{array}{l}\text { Mestrado, } \\
\text { Doutorado e } \\
\text { Mestrado } \\
\text { Profissional }\end{array}$ \\
\hline 3 & $\begin{array}{l}\text { Universidade Federal de Minas Gerais } \\
\text { (UFMG) }\end{array}$ & MG & 1976 & $\begin{array}{l}\text { Ciência da } \\
\text { Informação/ } \\
\text { Gestão e }\end{array}$ & $\begin{array}{l}\text { Mestrado e } \\
\text { Doutorado } \\
\text { (ambos } \\
\text { cursos) }\end{array}$ \\
\hline
\end{tabular}




\begin{tabular}{|c|c|c|c|c|c|}
\hline & & & & $\begin{array}{l}\text { Organização do } \\
\text { Conhecimento }\end{array}$ & \\
\hline 4 & $\begin{array}{l}\text { Universidade Federal da Paraíba } \\
\text { (UFPB) }\end{array}$ & PB & 1977 & $\begin{array}{l}\text { Ciência da } \\
\text { Informação }\end{array}$ & $\begin{array}{l}\text { Mestrado e } \\
\text { Doutorado }\end{array}$ \\
\hline 5 & Universidade de Brasília (UNB) & $\mathrm{DF}$ & 1978 & $\begin{array}{l}\text { Ciência da } \\
\text { Informação }\end{array}$ & $\begin{array}{l}\text { Mestrado e } \\
\text { Doutorado }\end{array}$ \\
\hline 6 & Universidade Federal da Bahia (UFBA) & $\mathrm{BA}$ & 1978 & $\begin{array}{l}\text { Ciência da } \\
\text { Informação }\end{array}$ & $\begin{array}{l}\text { Mestrado e } \\
\text { Doutorado }\end{array}$ \\
\hline 7 & $\begin{array}{l}\text { Universidade Estadual Paulista Júlio } \\
\text { de Mesquita Filho (UNESP) }\end{array}$ & SP & 1998 & $\begin{array}{l}\text { Ciência da } \\
\text { Informação }\end{array}$ & $\begin{array}{l}\text { Mestrado e } \\
\text { Doutorado }\end{array}$ \\
\hline 8 & $\begin{array}{l}\text { Universidade Federal de Santa } \\
\text { Catarina (UFSC) }\end{array}$ & SC & 2003 & $\begin{array}{l}\text { Ciência da } \\
\text { Informação }\end{array}$ & $\begin{array}{l}\text { Mestrado e } \\
\text { Doutorado }\end{array}$ \\
\hline 9 & $\begin{array}{l}\text { Universidade Estadual de Londrina } \\
\text { (UEL) }\end{array}$ & PR & 2007 & $\begin{array}{l}\text { Ciência da } \\
\text { Informação }\end{array}$ & $\begin{array}{l}\text { Mestrado e } \\
\text { Doutorado }\end{array}$ \\
\hline 10 & $\begin{array}{l}\text { Universidade Federal de Pernambuco } \\
\text { (UFPE) }\end{array}$ & $\mathrm{PE}$ & 2008 & $\begin{array}{l}\text { Ciência da } \\
\text { Informação }\end{array}$ & $\begin{array}{l}\text { Mestrado e } \\
\text { Doutorado }\end{array}$ \\
\hline 11 & $\begin{array}{l}\text { Universidade Federal Fluminense } \\
\text { (UFF) }\end{array}$ & RJ & 2009 & $\begin{array}{l}\text { Ciência da } \\
\text { Informação }\end{array}$ & $\begin{array}{l}\text { Mestrado e } \\
\text { Doutorado }\end{array}$ \\
\hline 12 & $\begin{array}{l}\text { Universidade Federal do Estado do } \\
\text { Rio De Janeiro (UNIRIO) }\end{array}$ & RJ & 2012 & $\begin{array}{l}\text { Biblioteconomia/ } \\
\text { Gestão de } \\
\text { Documentos e } \\
\text { Arquivos }\end{array}$ & $\begin{array}{l}\text { Mestrado } \\
\text { Profissional } \\
\text { (ambos } \\
\text { cursos) }\end{array}$ \\
\hline 13 & $\begin{array}{l}\text { Universidade do Estado de Santa } \\
\text { Catarina (UDESC) }\end{array}$ & SC & 2013 & $\begin{array}{l}\text { Gestão de } \\
\text { Informação }\end{array}$ & $\begin{array}{l}\text { Mestrado } \\
\text { Profissional }\end{array}$ \\
\hline 14 & Universidade FUMEC (FUMEC) & $M G$ & 2013 & $\begin{array}{l}\text { Sistema de } \\
\text { Informação/ } \\
\text { Gestão do } \\
\text { Conhecimento }\end{array}$ & $\begin{array}{l}\text { Mestrado e } \\
\text { Doutorado }\end{array}$ \\
\hline 15 & $\begin{array}{l}\text { Universidade Federal do Rio Grande } \\
\text { do Norte (UFRN) }\end{array}$ & $\mathrm{RN}$ & 2015 & $\begin{array}{l}\text { Gestão da } \\
\text { Informação e do } \\
\text { Conhecimento }\end{array}$ & $\begin{array}{l}\text { Mestrado } \\
\text { Profissional }\end{array}$ \\
\hline 16 & $\begin{array}{l}\text { Fundação Casa de Rui Barbosa } \\
\text { (FCRB) }\end{array}$ & RJ & 2016 & $\begin{array}{l}\text { Memória e } \\
\text { Acervos }\end{array}$ & $\begin{array}{l}\text { Mestrado } \\
\text { Profissional }\end{array}$ \\
\hline 17 & $\begin{array}{l}\text { Universidade Federal de São Carlos } \\
\text { (UFSCAR) }\end{array}$ & SP & 2016 & $\begin{array}{l}\text { Ciência da } \\
\text { Informação }\end{array}$ & Mestrado \\
\hline 18 & Universidade Federal do Cariri (UFCA) & CE & 2016 & Biblioteconomia & $\begin{array}{l}\text { Mestrado } \\
\text { Profissional }\end{array}$ \\
\hline 19 & Universidade Federal do Ceará (UFC) & CE & 2016 & $\begin{array}{l}\text { Ciência da } \\
\text { Informação }\end{array}$ & Mestrado \\
\hline 20 & $\begin{array}{l}\text { Fundação Universidade Federal de } \\
\text { Sergipe (FUFSE) }\end{array}$ & SE & 2017 & $\begin{array}{l}\text { Ciência da } \\
\text { Informação }\end{array}$ & $\begin{array}{l}\text { Mestrado } \\
\text { Profissional }\end{array}$ \\
\hline 21 & Universidade Federal do Pará (UFPA) & PA & 2017 & $\begin{array}{l}\text { Ciência da } \\
\text { Informação }\end{array}$ & Mestrado \\
\hline 22 & $\begin{array}{l}\text { Universidade Federal de Alagoas } \\
\text { (UFAL) }\end{array}$ & $\mathrm{AL}$ & 2018 & $\begin{array}{l}\text { Ciência da } \\
\text { Informação }\end{array}$ & Mestrado \\
\hline 23 & $\begin{array}{l}\text { Universidade Federal do Rio Grande } \\
\text { do Sul (UFRGS) }\end{array}$ & RS & 2018 & $\begin{array}{l}\text { Ciência da } \\
\text { Informação }\end{array}$ & Mestrado \\
\hline 24 & $\begin{array}{l}\text { Universidade Federal do Espírito } \\
\text { Santo (UFES) }\end{array}$ & ES & 2019 & $\begin{array}{l}\text { Ciência da } \\
\text { Informação }\end{array}$ & Mestrado \\
\hline
\end{tabular}

Fonte: criação dos autores com base em Coordenação de Aperfeiçoamento de Pessoal de Nível Superior (CAPES) ${ }^{3}$, Pinheiro (2007) e Souza \& Stumpf (2009).

${ }^{3}$ Cursos Avaliados e Reconhecidos. Disponível em:https://sucupira.capes.gov.br/sucupira/public/consultas/coleta/programa/quantitativos/quan titativoles.jsf?areaAvaliacao=31\&areaConhecimento=60700009. Acesso em: 09 jun. 2020. 
É evidente que a partir dos anos 2000 ocorreu um aumento significativo dos cursos de pós-graduação de Ciência da Informação no país, no nível de mestrado, pois até 2003 existiam sete cursos distribuídos em quatro na região Sudeste, dois no Nordeste e um no Distrito Federal.Em 2020, 50 anos após o primeiro curso na área, de acordo com a CAPES, existem 40 cursos distribuídos em 24 universidades, sendo8 mestrados profissionais, 19 mestrados e 13 doutorados.

A fim de perceber a capilaridade de influência do PPGCI IBICT como formador de profissionais qualificados, foram analisados os dados coletados dos 50 anos versus o quadro de docentes dos cursos de pós-graduação em Ciência da Informação, no ano de 2020, de acordo com a CAPES. O resultado revelou a presença de ex-alunos do PPGCI como docentes nas seguintes universidades: UFMG, UFSCAR, UFCA, UFPA, UFRGS, FCRB, UFBA, UFPB, UFF, UNIRIO e UFRJ, conforme a Figura 1.

\section{Figura 1 -Atuação de Ex-alunos do IBICT em outros PPGCI em 2020}

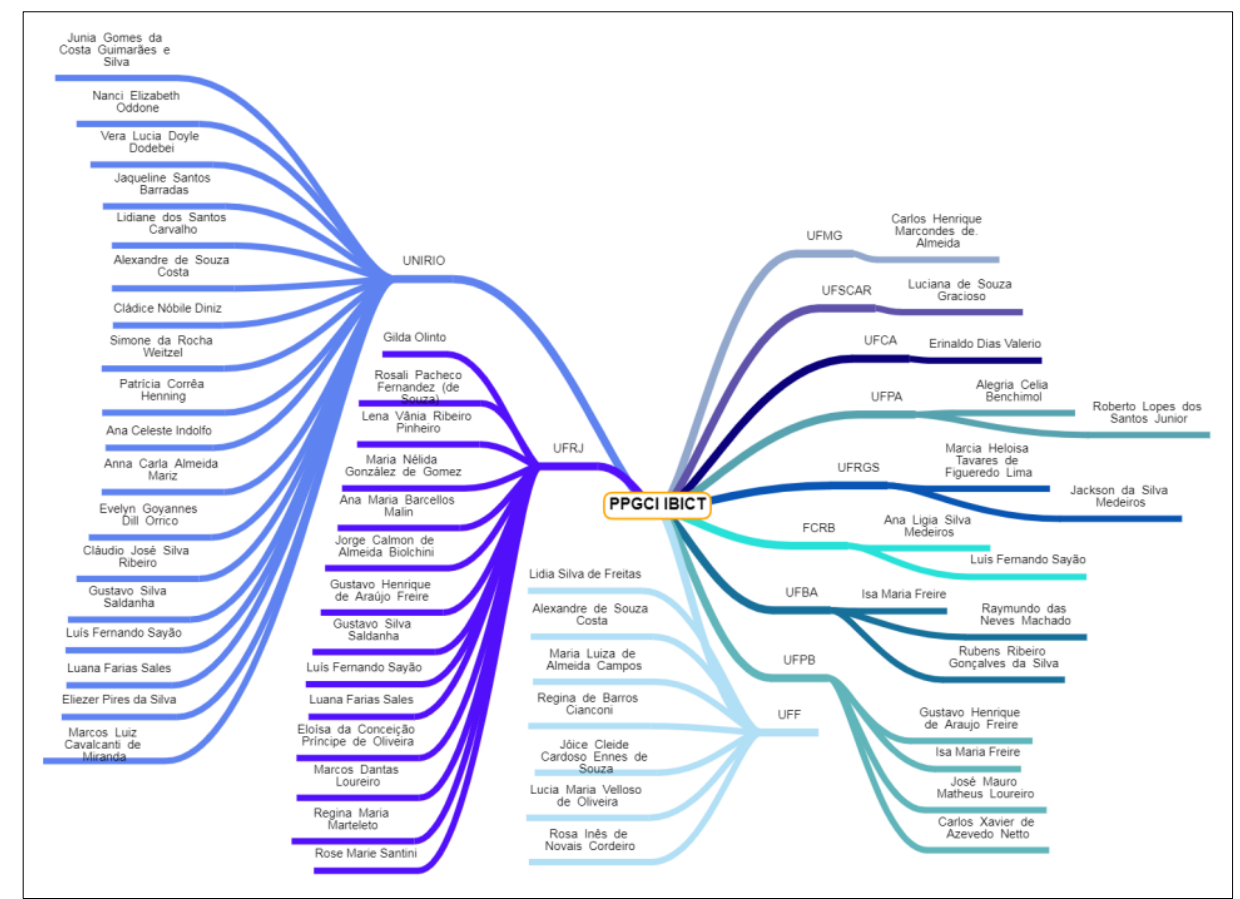

Fonte: criação dos autores com base em dados de websitesdos PPGCl em $2020^{4}$

\footnotetext{
${ }^{4}$ As professoras Regina Marteleto e Gilda Olindo fizeram parte linha de pesquisa em "informação, cultura e sociedade" a partir de 1985 (PINHEIRO; LOUREIRO,1995).
} 


\section{METODOLOGIA}

A pesquisa de caráter empírico exploratório realizou a análise de conteúdo de 752 títulos e 454 resumos de teses (169) e dissertações (583) do Programa de Pós-Graduação em Ciência da Informação (PPGCl),do Instituto Brasileiro de Informação em Ciência e Tecnologia (IBICT) referente aos 50 anos do programa, de 1970 até março/2020, por meio de coleta de dados nos seguintes repositórios: Catálogo de Teses e Dissertações da Coordenação de Aperfeiçoamento de Pessoal de Nível Superior (CAPES)5, Biblioteca Digital Brasileira de Teses e Dissertações (BDTD)6, Repositório Institucional do IBICT (RIDI)7, Pantheon Repositório Institucional da Universidade Federal do Rio de Janeiro (UFRJ)8 e Repositório Institucional da Universidade Federal Fluminense (RIUFF)9.É necessário explicar que na consolidação dos dados foi identificada a falta de $298(39,63 \%)$ resumos e, por isso, os títulos foram incluídos na análise dos dados.

Na primeira etapa foi realizada a coleta, consolidação e tratamento dos dados(retirada de acentos, símbolos etc.)gerando um corpus textual, identificado por asteriscos $\left({ }^{* * *}{ }^{*} \mathrm{Cl} 50\right)$, salvo na extensão de texto (txt), para análise através do programa IRaMuTeQ (Interface de R pour les Analyses Multidimensionnelles de Textes et de Questionnaires). Este programa foi desenvolvido por Pierre Ratinaud, no Laboratoire d'Études et de Recherches Appliquées en Sciences Sociales, da Universidade de Toulouse, na França, com o objetivo de quantificar as estruturas significativas contidas em um texto de maneira a permitir a identificação da informação essencial nele contida.

Esta ferramenta de processamento de dados permite análises estatísticas sobre corpora textuais, ancorado ao software $\mathrm{R}$ e na linguagem Python, mas com certa limitação para gigantescos volumes de dados (big data).A maior vantagem

\footnotetext{
${ }^{5}$ CAPES. Disponível em: https://catalogodeteses.capes.gov.br/catalogo-teses/\#!/. Acesso em: 12 jun. 2020.

${ }^{6}$ BDTD. Disponível em: http://bdtd.ibict.br/vufind/. Acesso em: 12 jun. 2020.

7 RIDI. Disponível em: https://ridi.ibict.br. Acesso em: 12 jun. 2020.

8 Pantheon. Disponível em: https://pantheon.ufrj.br. Acesso em: 12 jun. 2020.

${ }_{9}^{9}$ RIUFF.Disponível em: https://app.uff.br/riuff/. Acesso em: 12 jun. 2020.
} 
do programa é sua capacidade de analisar diferentes fontes informacionais, tais como: entrevistas, artigos, reportagens e postagens em redes sociais, permitindo identificar temas, ideias e domínios contidos no corpus textual, por meio da interpretação do pesquisador. (CAMARGO; JUSTO, 2013).

$\mathrm{Na}$ análise dos dados foi levada em consideração a classificação das áreas do conhecimento do Conselho Nacional de Desenvolvimento Científico e Tecnológico (CNPq) em relação à Ciência da Informação, subárea das Ciências Sociais Aplicadas, a fim de contribuir com termos que permitisse a identificação do campo científico no corpus, conforme Figura 2.

Figura 2 -Áreas do Conhecimento da Ciência da Informação

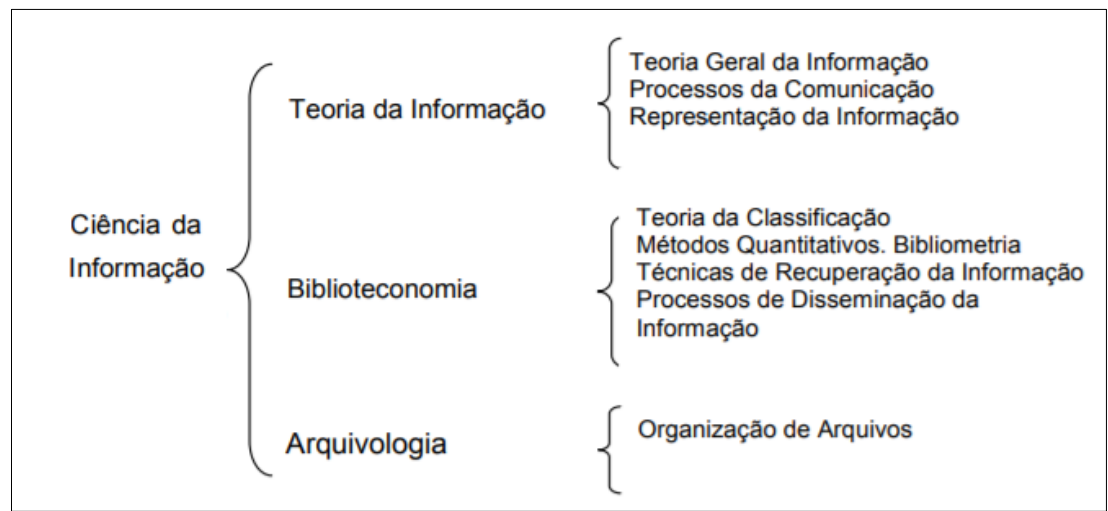

Fonte: classificação do $\mathrm{CNPq}^{10}$ e Souza \& Ribeiro (2009)

\section{RESULTADOS}

A primeira análise textual do IRaMuTeQ foi a Classificação Hierárquica de Descendente (CHD) que permite a análise lexical das palavras contidas no corpus textual, dividindo em segmentos de textos conforme a frequência das palavras, realizando a lematização dos termos, ou seja, a redução de uma palavra flexionada a sua parte essencial, e produzindo uma visualização hierárquica dos termos por classes chamado dendrograma. A partir da análise dos segmentos de textos contidos nas classes geradas pelo programa é possível inferir sobre ideias e temas contidos no corpus textual (SACERDOTE, 2018).

\footnotetext{
10 Tabela de Áreas do Conhecimento. Disponível em: <http://lattes.cnpq.br/documents/ 11871/24930/TabeladeAreasdoConhecimento.pdf/d192ff6b-3e0a-4074-a74dc280521bd5f7>. Acesso em: 12 jun. 2020
} 
O resultado da CHD apresentou 2.673 segmentos de textos, representando 10.699 formas compostas de 7.288 ativas (substantivo, adjetivo e adverbio) e 418 suplementares (artigos definidos, pronomes, conjunção etc.), formando 4 classes, exibidas na Figura 3. Ademais, o percentual de cada classe representa a proporção na separação do corpus do vocabulário total (100\%).

Figura 3- Dendrograma da Produção Acadêmica do PPGCI

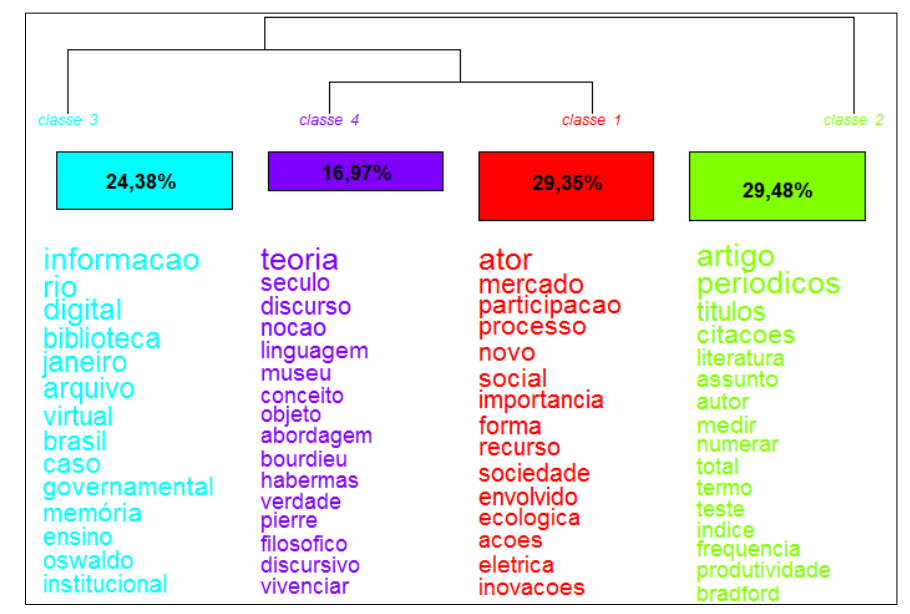

Fonte:resultadobaseado no IRaMuTeQ

A partir do resultado da CHD foram analisados os segmentos de textos e gráficos de palavras visando identificar as principais ideias contidas nas classes: 1) Classe1 (vermelho) apontou temas voltados para os usos e os efeitos da informação, como:a) movimentos sociais, dinâmicas informacionais e comunicacionais, e seus atores envolvidos; b) participação social no licenciamento ambiental, crise ecológica e produção de energia elétrica;c) recursos informacionais na produção de saberes científicos, atores e fluxos informacionais no processo de inovação;d) adoção e cotas raciais em instituições de ensino superior público;e) tecnologias abertas e sociais, cultura colaborativa, redes digitais, recursos tecnológicos na educação.

2) Classe2 (verde)apresentou temas que fazem parte das metrias da informação, como: a) análise de concentração e dispersão de citações por artigo e livro; b) títulos como ponto de acesso e incorporados ao processo KWIC (sistema de palavras-chave do contexto)de indexação; c) revistas mais citadas; d) análise de literatura (material, origem etc.); d) lei de Bradford; e) análise de produtividade de artigos por meio de citações e pedidos de cópias. 
3) Classe3 (azul) mostrou temas ligados às instituições e empresas sediadas no Rio de Janeiro, como: a) representação da informação na Biblioteca Nacional do Brasil; b) memória institucional do Colégio Pedro II; c) uso da CAPES por professores da UFRJ; d) fluxo de informações em agências de turismo; e) artigos científicos indexados no repositório de saúde pública da Fundação Oswaldo Cruz (Fiocruz).

4) Classe 4 (roxo) revelou temas teóricos e conceituais, como: a) teorias do agir comunicativo e do discurso de Habermas; b) conceito de trivialité de Jeanneret; c) teoria da classificação facetada de Ranganathan; d) fundamentos da semiótica e teoria da representação; e) Organização do conhecimento.

A segunda análise textual foi a Similitude, baseada na teoria dos grafos, "possibilita representar graficamente a estrutura de um corpus, distinguindo também as partes comuns e as especificidades". (MARCHAND; RATINAUD, 2012), conforme Figura 4.

Figura 4 -Similitude da Produção Acadêmica do PPGCI

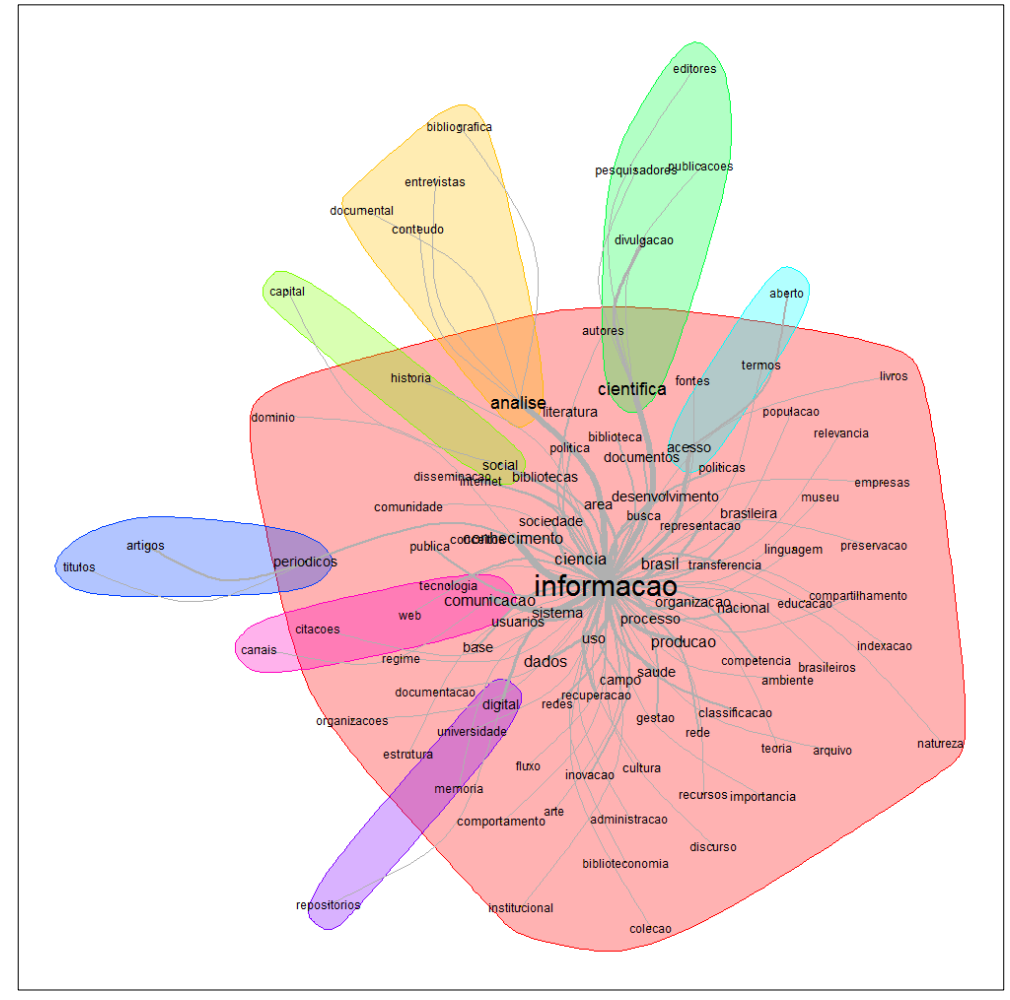

Fonte: resultado baseado no IRaMuTeQ

O grafo exibiu um cluster principal representado pelo termo "informação" 
que possui atração semântica com os seguintes termos: "ciência", "brasil”,"organização", "processo", "sistema", "comunicação" e "conhecimento". Além disso, o cluster central é composto por mais sete subclusters identificados pelos termos: "digital”, "comunicação", periódicos", "social”, "análise”, científica" e "acesso". O primeiro subcluster apontou que o termo "digital" está ligado aos termos: "universidade", "memoria" e "repositórios". O segundo subcluster mostrou que "comunicação" está ligado aos termos: "tecnologia", "web", "citações" e "canais". O terceiro subcluster mostrou que "periódicos" possui ligação com os termos: "artigos" e "títulos". O quarto subcluster apontou que "social" está ligado aos termos: "história" e "capital". O quinto subcluster mostrou que "análise" está ligado aos termos: "conteúdo", "documental", "entrevistas" e "bibliográfica". O sexto subcluster sinalizou que "cientifica" possui ligação com os termos: "autores", "divulgação", "pesquisadores" e "publicações". O sétimo subcluster demonstrou que "acesso" está ligado aos termos: "fontes", "termos" e "aberto".

A terceira análise textual foi a frequência simples das palavras que resultou na nuvem de palavras retratada na Figura 5, que possibilita rápida identificação das palavras-chave de um corpus textual (CAMARGO; JUSTO, 2013). Esta análise permite uma verificação ou ratificação dos insights realizados nas análises anteriores.

Figura 5 - Nuvem de Palavras da Produção Acadêmica do PPGCI

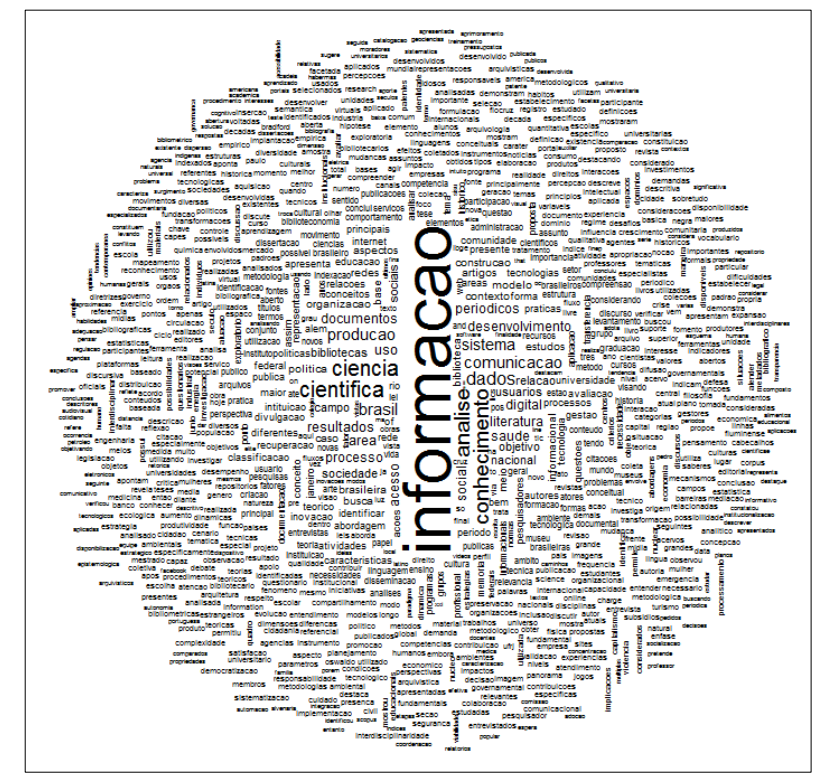

Fonte: resultado baseado no IRaMuTeQ 
A nuvem de palavras mostrou "informação"como palavra mais relevante no corpus, visto que é a palavra de maior frequência com 1.595 ocorrências. Notou-se também que as seguintes palavras se destacaram: "ciência" (408 ocorrências), "científica" (403 ocorrências), "análise" (394 ocorrências), "conhecimento" (370 ocorrências), "dados" (298 ocorrências), "comunicação" (264 ocorrências), "produção" (257 ocorrências) e "sistema" (244 ocorrências).

\section{DISCUSSÃO DOS DADOS}

O resultado da análise das classes da CHD apontou para temas que estão relacionados às linhas de pesquisas e áreas de interesse do corpo docente do PPGCI - 2020, conforme Quadro 5.

\section{Quadro 5-Linha de Pesquisas, Corpo Docente e Áreas de Interesse}

\begin{tabular}{|c|c|c|}
\hline 옹 & Docente & Área de Interesse \\
\hline 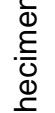 & Angélica Alves da Cunha Marques & $\begin{array}{l}\text { Arquivologia e Ciência da Informação: trajetórias } \\
\text { histórico-epistemológicas de internacionalização e } \\
\text { institucionalização. }\end{array}$ \\
\hline$\overline{\check{O}}$ & Eloisa da Conceição Príncipe de Oliveira & $\begin{array}{l}\text { Comunicação científica e suas metrias, periódicos } \\
\text { científicos. }\end{array}$ \\
\hline $\begin{array}{l}\bar{\sigma} \\
0 \\
0 \\
0\end{array}$ & Fabio Castro Gouveia & $\begin{array}{l}\text { Webometria, Cibermetria, disseminação e } \\
\text { comunicação em saúde. }\end{array}$ \\
\hline 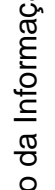 & Gustavo Henrique de Araújo Freire & $\begin{array}{l}\text { Gestão e comunicação da informação; comunicação e } \\
\text { divulgação científica; redes de aprendizagem; políticas } \\
\text { regimes e competências em informação; políticas de } \\
\text { informação; socialização da informação; redes sociais } \\
\text { digitais; epistemologia. }\end{array}$ \\
\hline $\begin{array}{l}\frac{\pi}{0} \\
\stackrel{10}{0} \\
0 \\
0 \\
0 \\
0\end{array}$ & Gustavo Silva Saldanha & $\begin{array}{l}\text { Filosofia, linguagem e informação; pragmática, } \\
\text { retórica, ética e teorias da informação; formas } \\
\text { simbólicas e organização do conhecimento; } \\
\text { epistemologia, instituições, sujeitos, práticas. }\end{array}$ \\
\hline$\stackrel{\substack{N \\
\mathbb{N}}}{=}$ & Jacqueline Leta & $\begin{array}{l}\text { Bibliometria e Cientometria com ênfase na produção } \\
\text { científica brasileira, ciência e saúde, ciência e gênero. }\end{array}$ \\
\hline ర్ & Jorge Calmon de Almeida Biolchini & $\begin{array}{l}\text { Organização do conhecimento e gestão da informação } \\
\text { em saúde. }\end{array}$ \\
\hline : & Lena Vania Ribeiro Pinheiro & $\begin{array}{l}\text { História e epistemologia da Ciência da Informação; } \\
\text { comunicação e divulgação científica; Bibliometria, } \\
\text { Informetria e informação e arte. }\end{array}$ \\
\hline (ָ) & Luana Sales & $\begin{array}{l}\text { Dados de pesquisa, curadoria digital, E-Science; } \\
\text { ontologias, Biblioteconomia. }\end{array}$ \\
\hline $\begin{array}{l}0 \\
\stackrel{\sim}{\sigma}\end{array}$ & Luís Fernando Sayão & $\begin{array}{l}\text { Dados de pesquisa, curadoria digital, ontologias, } \\
\text { preservação digital; E-Science. }\end{array}$ \\
\hline$\frac{.05}{\bar{O}}$ & Marcelo Fornazin & $\begin{array}{l}\text { Informática em saúde, tecnologias sociais, informática } \\
\text { e sociedade, gestão de tecnologia da informação. }\end{array}$ \\
\hline$\frac{0}{2}$ & Marcos do Couto Bezerra Cavalcanti & $\begin{array}{l}\text { Gestão do conhecimento, inteligência empresarial, } \\
\text { ativos intangíveis, governo eletrônico. }\end{array}$ \\
\hline$\frac{\widetilde{\pi}}{\stackrel{\Gamma}{\Xi}}$ & Paulo César Castro & $\begin{array}{l}\text { Internet, redes sociais e sociedade; informação, big } \\
\text { data, algoritmos e cultura; TICs e mediatização; } \\
\text { semiótica e análise do discurso. }\end{array}$ \\
\hline
\end{tabular}




\begin{tabular}{|c|c|c|}
\hline & Ricardo M. Pimenta & $\begin{array}{l}\text { Humanidades digitais, metodologia, informação e } \\
\text { memória, conhecimento, poder e cultura digital; } \\
\text { documento. }\end{array}$ \\
\hline & Rosali Fernandez de Souza & $\begin{array}{l}\text { Organização e representação do conhecimento e da } \\
\text { informação, classificação. }\end{array}$ \\
\hline \multirow{12}{*}{ 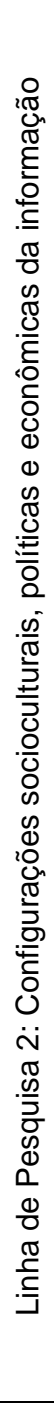 } & Docente & Área de Interesse \\
\hline & Ana Maria Barcellos Malin & $\begin{array}{l}\text { Informação, conhecimento e gestão na área } \\
\text { governamental. }\end{array}$ \\
\hline & Arthur Coelho Bezerra & $\begin{array}{l}\text { Teoria crítica da informação; vigilância, filtragem } \\
\text { algorítmica, privacidade e segurança no novo regime } \\
\text { de informação; ética e competência crítica em } \\
\text { informação. }\end{array}$ \\
\hline & Gilda Olinto & $\begin{array}{l}\text { Condicionantes socioculturais das TICs; biblioteca } \\
\text { pública, inclusão digital, competência em informação, } \\
\text { gênero e ciência, indicadores de C\&T. }\end{array}$ \\
\hline & Giuseppe Mario Cocco & $\begin{array}{l}\text { Informação e trabalho, comunicação, globalização, } \\
\text { cidade e cidadania, capitalismo cognitivo. }\end{array}$ \\
\hline & Liz-Rejane Issberner & $\begin{array}{l}\text { Informação, conhecimento, inovação, } \\
\text { desenvolvimento socioambiental, desenvolvimento } \\
\text { local, redes sociais e tecnológicas. }\end{array}$ \\
\hline & Marco André Feldman Schneider & $\begin{array}{l}\text { Ética, política, epistemologia e competência crítica em } \\
\text { informação }\end{array}$ \\
\hline & Marcos Dantas & $\begin{array}{l}\text { Economia política da informação, comunicação e } \\
\text { cultura, políticas públicas e regulamentação de } \\
\text { tecnologias digitais, propriedade intelectual. }\end{array}$ \\
\hline & Maria Nélida Gonzalez de Gómez & $\begin{array}{l}\text { Estudos sócio epistemológicos da informação; } \\
\text { políticas da informação e regime de informação. }\end{array}$ \\
\hline & Regina Maria Marteleto & $\begin{array}{l}\text { Cultura, informação, sociedade; informação e saúde; } \\
\text { mediações informacionais em redes e movimentos } \\
\text { sociais; sujeito, leituras e linguagens de informação }\end{array}$ \\
\hline & Rose Marie Santini & $\begin{array}{l}\text { Sociologia da internet, sociologia da cultura; } \\
\text { microssociologia aplicada a estudos de rede; redes } \\
\text { sociais online e suas consequências socioculturais; } \\
\text { curadoria algorítmica e sistemas de recomendação } \\
\text { online; manipulação e desinformação nas redes } \\
\text { sociais; social bots; propaganda computacional; } \\
\text { comportamento e manipulação da opinião pública } \\
\text { online. }\end{array}$ \\
\hline & Sarita Albagli & $\begin{array}{l}\text { Informação, conhecimento, poder e política; } \\
\text { tecnologias da informação e comunicação e inovação } \\
\text { social; produção colaborativa e Ciência Aberta; } \\
\text { informação, redes sociotécnicas e território. }\end{array}$ \\
\hline
\end{tabular}

Fonte: criação dos autores com base no PPGCI IBICT/UFRJ $2020^{11}$

Os temas identificados nas classes 2 e 4 sobre abordagens teóricas e conceituais, como também metrias da informação podem ser observadas na linha de pesquisa 1. Os temas da classe 1 sobre os usos e efeitos da informação no âmbito ético, social e político referem-se a linha de pesquisa 2. Já os temas da classe 3 sobre estudos relacionados às instituições e empresas sediadas no Rio de Janeiro, podem ser enquadrados em ambas as linhas de pesquisa 1 e 2.

\footnotetext{
11 PPGCI IBICT UFRJ. Disponível em:<http://www.ppgci.ufrj.br/pt>. Acesso em: 22 jun. 2020.
} 
Ademais, é interessante perceber que estudos relacionados ao Rio de Janeiro tiveram destaque na análise do IRaMuTeQ, o que nos permite inferir que talvez exista uma relação com profissionais de instituições e organizações sediadas no Rio de Janeiro, que estudaram no PPGCl, e realizaram pesquisas sobre as empresas em que trabalhavam.

A centralidade do termo "informação" na Nuvem de Palavras e na Similitude permitiu concluir que a informação é o objeto de estudo principal das teses e dissertações na Ciência da Informação. Além disso, os termos mais recorrentes apresentados na Nuvem de Palavras mostraram correspondência com as áreas de interesse descritas no Quadro 5 como, por exemplo, comunicação e divulgação científica, curadoria de dados, e-Science, organização do conhecimento e produção colaborativa.

A análise de Similitude permitiu identificar o conceito e a abrangência da Ciência da Informação através dos termos como uma ciência que estuda fenômenos e processos. Segundo Goffman (1970):

O objetivo de uma disciplina da ciência da informação deve ser o de estabelecer uma abordagem científica unificada para o estudo dos vários fenômenos que envolvem a noção de informação, se tais fenômenos são encontrados em processos biológicos, na existência humana ou nas máquinas criadas por seres humanos. Consequentemente, a disciplina deve se preocupar com o estabelecimento de um conjunto de princípios fundamentais que regem o comportamento de todos os processos de comunicação e seus sistemas de informação associados. (GOFFMAN, 1970, p.591) ${ }^{12}$.

A Similitude possibilitou o agrupamento de termos em categorias temáticas, o que proporcionou uma melhor percepção dos assuntos abordados em teses e dissertações: a) memória-digital; b) repositório-universidade; c) canais-comunicação; d) tecnologia-web; e) artigos-periódicos; f) capital-social; g) análise-bibliográficas; h) conteúdo-entrevistas; i) autores-publicações; j) divulgação-científica; I) acesso-aberto; m) termos-fontes.

12 Tradução nossa: The aim of a discipline of information science must be that of establishing a unified scientific approach to the study of the various phenomena involving the notion of information whether such phenomena are found in biological processes, human existence or the machines created by human beings. Consequently, the subject must be concerned with the establishment of a set of fundamental principles governing the behavior of all communication processes and their associated information systems. 
Os termos apresentados na análise de Similitude demonstraram uma correlação com os temas abordados pelos grupos de pesquisa do PPGCl, conforme Quadro 6.

Quadro 6 - Grupos de Pesquisa e Análise de Similitude

\begin{tabular}{|c|c|c|}
\hline Grupo & Descrição & Similitude (termos) \\
\hline $\begin{array}{l}\text { Comunicação e } \\
\text { Divulgação } \\
\text { Científicas }\end{array}$ & $\begin{array}{l}\text { Comunicação Científica, sob a abordagem da } \\
\text { Ciência da Informação e com fundamentação na } \\
\text { História e Sociologia da Ciência. Pesquisas em } \\
\text { comunidades estrangeiras e brasileiras de C\&T, } \\
\text { abrangendo canais de comunicação e } \\
\text { informação, inclusive eletrônicos. }\end{array}$ & $\begin{array}{l}\text { "comunicação", } \\
\text { "periódicos", } \\
\text { "científica", "acesso", } \\
\text { "digital", "citações", } \\
\text { "canais", "artigos", } \\
\text { "títulos", "divulgação", } \\
\text { "pesquisadores", } \\
\text { "publicações" e } \\
\text { "fontes". }\end{array}$ \\
\hline $\begin{array}{l}\text { Cultura e } \\
\text { Processos Info- } \\
\text { comunicacionais }\end{array}$ & $\begin{array}{l}\text { Estudos sobre os processos info- } \\
\text { comunicacionais nos ambientes locais da } \\
\text { cultura e sua relação com as experiências } \\
\text { interculturais, na perspectiva do uso e da } \\
\text { apropriação social de conhecimentos no campo } \\
\text { da saúde e áreas afins. A partir de uma } \\
\text { abordagem relacional das questões info- } \\
\text { comunicacionais, passou a estudar as } \\
\text { correlações entre as redes sociais e as redes } \\
\text { textuais. }\end{array}$ & $\begin{array}{l}\text { "transferência", } \\
\text { "processo", "sistema", } \\
\text { "conhecimento", } \\
\text { "digital", } \\
\text { "comunicação", } \\
\text { "social", "tecnologia", } \\
\text { "web". }\end{array}$ \\
\hline $\begin{array}{l}\text { Ecce Liber: } \\
\text { filosofia, linguagem } \\
\text { e organização dos } \\
\text { saberes }\end{array}$ & $\begin{array}{l}\text { A proposta do grupo é desenvolver os estudos } \\
\text { bibliológicos a partir da Filosofia do Livro e dos } \\
\text { saberes afins, constituindo um espaço crítico- } \\
\text { epistemológico de reflexão sobre o conceito de } \\
\text { livro e suas manifestações físico-simbólicas. O } \\
\text { grupo tem como linhas gerais de argumentação } \\
\text { os estudos epistemológicos e históricos da } \\
\text { Biblioteconomia \& Ciência da Informação. Seu } \\
\text { nascimento está ligado à questão da "finalidade } \\
\text { do livro", ou seja, o conjunto de } \\
\text { questionamentos sobre as relações entre } \\
\text { conhecimento e registro do conhecimento, hoje } \\
\text { expressas centralmente sob o conceito de } \\
\text { informação. }\end{array}$ & $\begin{array}{l}\text { "conhecimento", } \\
\text { "memória", "história", } \\
\text { "documental", } \\
\text { "bibliografias" e } \\
\text { "fontes". }\end{array}$ \\
\hline $\begin{array}{l}\text { Estudos Críticos } \\
\text { em Informação, } \\
\text { Tecnologia e } \\
\text { Organização Social } \\
\text { (Escritos) }\end{array}$ & $\begin{array}{l}\text { Temos interesse em produzir diagnósticos } \\
\text { críticos sobre as características dos diferentes } \\
\text { regimes de informação existentes, incluindo o } \\
\text { regime global de informação que vigora nas } \\
\text { redes digitais. Queremos saber como se } \\
\text { originam e se estabilizam, como influenciam } \\
\text { questões ético-políticas e como formas } \\
\text { específicas de poder são exercidas em tais } \\
\text { regimes, destacando os diferentes papéis dos } \\
\text { agentes na organização socioeconômica e os } \\
\text { fatores que promovem desigualdades no acesso } \\
\text { à informação. Ao mesmo tempo, nos dedicamos } \\
\text { a aprofundar os estudos teóricos e os aportes } \\
\text { práticos no tema da competência em } \\
\text { informação, com destaque para as contribuições }\end{array}$ & $\begin{array}{l}\text { "organização", } \\
\text { "processo", "uso", } \\
\text { "sistema", "digital", } \\
\text { "comunicação", } \\
\text { "social", "acesso", } \\
\text { "tecnologia", "web", } \\
\text { "capital" e "aberto". }\end{array}$ \\
\hline
\end{tabular}




\begin{tabular}{|c|c|c|}
\hline & $\begin{array}{l}\text { filosóficas, sociológicas e pedagógicas } \\
\text { presentes na perspectiva da competência crítica } \\
\text { em informação. }\end{array}$ & \\
\hline $\begin{array}{l}\text { Gênero, Ciência, } \\
\text { Tecnologia e } \\
\text { Sociedade }\end{array}$ & $\begin{array}{l}\text { O Grupo aborda questões teóricas e produz } \\
\text { análises empíricas relacionadas ao papel, } \\
\text { acesso e contribuição das mulheres no setor de } \\
\text { Ciência e Tecnologia no Brasil. Também se } \\
\text { debruça sobre o acesso e uso das tecnologias } \\
\text { de informação e de comunicação por mulheres } \\
\text { em diferentes setores, idades e perfis sociais. } \\
\text { Para isso, são utilizadas diferentes fontes e } \\
\text { bases informacionais, organizadas não apenas } \\
\text { por agências e institutos nacionais (como IBGE, } \\
\text { CNPq, Capes e SCIELO), mas também } \\
\text { instituições internacionais (como Unesco, } \\
\text { Thomson/ISI, Elsevier/Scopus e US National } \\
\text { Library of Medicine). }\end{array}$ & $\begin{array}{l}\text { "ciência”, "brasil", } \\
\text { "organização", } \\
\text { "processo", "uso", } \\
\text { "conhecimento", } \\
\text { "comunicação", } \\
\text { "acesso", } \\
\text { "universidade", } \\
\text { "repositórios", } \\
\text { "tecnologia", } \\
\text { "entrevistas", } \\
\text { "pesquisadores", } \\
\text { "publicações" e } \\
\text { "fontes". }\end{array}$ \\
\hline $\begin{array}{l}\text { Gestão do } \\
\text { conhecimento em } \\
\text { Ciências Nucleares }\end{array}$ & $\begin{array}{l}\text { O grupo de pesquisa Gestão do conhecimento } \\
\text { em ciências nucleares estuda soluções } \\
\text { estratégicas para a preservação, } \\
\text { compartilhamento e difusão dos conhecimentos } \\
\text { produzidos, tendo como elemento norteador o } \\
\text { desenvolvimento científico e tecnológico do país } \\
\text { na área nuclear. Os estudos do grupo de } \\
\text { pesquisa visam promover uma maior } \\
\text { aproximação entre a Ciência, Tecnologia e } \\
\text { Inovação na área nuclear e a sociedade, de } \\
\text { forma precisa e transparente. }\end{array}$ & $\begin{array}{l}\text { "ciência", "brasil", } \\
\text { "transferência", } \\
\text { "processo", } \\
\text { "conhecimento", } \\
\text { "comunicação" e } \\
\text { "acesso". }\end{array}$ \\
\hline $\begin{array}{l}\text { Informação, } \\
\text { Conhecimento e } \\
\text { Mudança } \\
\text { Sociotécnica }\end{array}$ & $\begin{array}{l}\text { O Grupo de Pesquisa dirige-se para a } \\
\text { compreensão do papel da informação e do } \\
\text { conhecimento nos atuais processos de } \\
\text { mudança sociotécnica, em suas dimensões } \\
\text { político-institucional, produtiva e cultural. Situa } \\
\text { as dinâmicas de cooperação e conflito em torno } \\
\text { da produção, circulação e apropriação da } \\
\text { informação e do conhecimento no cerne das } \\
\text { formas de poder contemporâneas. Compreende } \\
\text { as transformaçães científico-tecnológicas em } \\
\text { curso - particularmente as novas tecnologias de } \\
\text { informação e comunicação - como parte de um } \\
\text { processo social mais amplo, em que } \\
\text { informação, conhecimento e inovação assumem } \\
\text { nova centralidade. Focaliza, nesse contexto, as } \\
\text { novas dinâmicas territoriais e seus } \\
\text { entrecruzamentos com as das redes } \\
\text { sociotécnicas. }\end{array}$ & $\begin{array}{l}\text { "transferência", } \\
\text { "processo', “uso', } \\
\text { "sistema", } \\
\text { "conhecimento", } \\
\text { "digital”, } \\
\text { "comunicação", "social", } \\
\text { "tecnologia", "web", } \\
\text { "capital", "análise", } \\
\text { "cientifica", "acesso" e } \\
\text { "aberto". }\end{array}$ \\
\hline $\begin{array}{l}\text { Informação, } \\
\text { Conhecimento, } \\
\text { Inovação e } \\
\text { Sustentabilidade } \\
\text { Ambiental }\end{array}$ & $\begin{array}{l}\text { O grupo se organiza em torno do tema da } \\
\text { inovação e sustentabilidade ambiental e seus } \\
\text { atravessamentos com as dinâmicas da } \\
\text { informação, conhecimento e aprendizado. Esse } \\
\text { tema central oferece as coordenadas para } \\
\text { estudos e pesquisas na área de indicadores e } \\
\text { políticas de ciência, tecnologia e inovação; } \\
\text { redes e sistemas de informação; adoção e } \\
\text { difusão de inovações nas organizações e } \\
\text { territórios produtivos; inovação e } \\
\text { sustentabilidade ambiental no contexto }\end{array}$ & $\begin{array}{l}\text { "ciência”, "brasil”, } \\
\text { "transferência", } \\
\text { "processo', "uso', } \\
\text { "sistema", } \\
\text { "conhecimento", } \\
\text { "comunicação", "social", } \\
\text { "tecnologia", "web" e } \\
\text { "capital". }\end{array}$ \\
\hline
\end{tabular}

Inf. Inf., Londrina, v. 25, n. 4, p. 117 -141, out./dez. 2020. 


\begin{tabular}{|c|c|c|}
\hline & $\begin{array}{l}\text { global/local; desenvolvimento vis-à-vis aspectos } \\
\text { socioambientais. }\end{array}$ & \\
\hline $\begin{array}{l}\text { Informação, } \\
\text { Memória e } \\
\text { Sociedade }\end{array}$ & $\begin{array}{l}\text { O grupo busca analisar em perspectiva ampla } \\
\text { as relações plurais existentes entre o processo } \\
\text { de produção, circulação e controle da } \\
\text { informação na sociedade contemporânea e } \\
\text { aquele da memória em sua dimensão cultural e } \\
\text { política. Destacamos a questão do acesso, } \\
\text { reconhecimento e uso da informação e da } \\
\text { memória enquanto elementos "estruturados e } \\
\text { estruturantes" do conhecimento e dos saberes. } \\
\text { Para tal, faz-se necessária a reflexão sobre o } \\
\text { acesso e circulação da informação, seus usos e } \\
\text { significações no âmbito das instituições- } \\
\text { memória existentes. Se configuram como } \\
\text { campos possíveis de investigação os arquivos, } \\
\text { bibliotecas, museus e centros culturais } \\
\text { enquanto "lugares de memória". Igualmente os } \\
\text { portais e sítios eletrônicos, públicos ou privados, } \\
\text { além de blogs e redes sociais. Nesse sentido, é } \\
\text { mister a reflexão sobre o papel do documento } \\
\text { "lato sensu" e das tecnologias de informação e } \\
\text { comunicação (TICs) para as ações de produção } \\
\text { e circulação da informação enquanto elementos } \\
\text { norteadores de políticas e movimentos } \\
\text { impetrados pela sociedade civil, de direito/dever } \\
\text { à memória. Tais fenômenos não apenas } \\
\text { produzem seus discursos, como podem se } \\
\text { coadunar às releituras e reconfigurações de } \\
\text { significados, representações e poderes } \\
\text { relacionados aos usos da informação. }\end{array}$ & $\begin{array}{l}\text { "ciência”, "brasil", "uso", } \\
\text { "conhecimento", } \\
\text { "social", "análise", } \\
\text { "cientifica", } \\
\text { "universidade", } \\
\text { "memória", 'repositório", } \\
\text { "tecnologia', "web", } \\
\text { "canais", "história", } \\
\text { "conteúdo", } \\
\text { "documental", } \\
\text { "entrevistas", } \\
\text { "bibliografias", } \\
\text { "publicações", "acesso" } \\
\text { e "fontes". }\end{array}$ \\
\hline $\begin{array}{l}\text { Organização do } \\
\text { Conhecimento }\end{array}$ & $\begin{array}{l}\text { As repercussões das atividades deste grupo se } \\
\text { darão principalmente nas áreas de Gestão e } \\
\text { Representação da Informação, Classificação do } \\
\text { Conhecimento e no Ensino e Pesquisa em } \\
\text { Ciência da Informação. }\end{array}$ & $\begin{array}{l}\text { "organização", } \\
\text { "processo", "uso", } \\
\text { "sistema', } \\
\text { "conhecimento,' } \\
\text { "comunicação", "social", } \\
\text { "análise”, "cientifica", } \\
\text { "tecnologia", "web", } \\
\text { "conteúdo", } \\
\text { "documental", "fontes" e } \\
\text { 'termos". }\end{array}$ \\
\hline $\begin{array}{l}\text { Perspectivas } \\
\text { Filosóficas em } \\
\text { Informação (Perfil-i) }\end{array}$ & $\begin{array}{l}\text { O objetivo geral do grupo é promover o estudo } \\
\text { dos clássicos da filosofia e das ciências } \\
\text { humanas e sociais, investigando como podem } \\
\text { contribuir para o debate atual em torno do } \\
\text { amplo conjunto de questões relacionadas à } \\
\text { informação e ao conhecimento, com ênfase nos } \\
\text { fundamentos, imbricações e implicações de } \\
\text { natureza ética, política e epistemológica da } \\
\text { ciência, da tecnologia e da inovação. }\end{array}$ & $\begin{array}{l}\text { "ciência", "processo", } \\
\text { "uso", "sistema', } \\
\text { "conhecimento', } \\
\text { "comunicação", "social”, } \\
\text { "análise", "cientifica”, } \\
\text { "tecnologia”, "web", } \\
\text { "conteúdo", } \\
\text { "documental", } \\
\text { "publicações" e"fontes". }\end{array}$ \\
\hline $\begin{array}{l}\text { Tecnologia de } \\
\text { Informação e } \\
\text { Sociedade }\end{array}$ & $\begin{array}{l}\text { O grupo de pesquisa focaliza características e } \\
\text { problemas relacionados à introdução e ao } \\
\text { desenvolvimento da área de tecnologia de } \\
\text { informação e comunicação (TIC) no país, assim } \\
\text { como da ciência e tecnologia em geral. Aborda } \\
\text { especificamente questões relativas à situação } \\
\text { atual e perspectivas do trabalho e das } \\
\text { ocupações nestas áreas visando a geração de }\end{array}$ & $\begin{array}{l}\text { "ciência”, "brasil”, } \\
\text { "transferência", } \\
\text { "organização", "uso", } \\
\text { "sistema", } \\
\text { "conhecimento", } \\
\text { "social", "análise", } \\
\text { "cientifica", "tecnologia", }\end{array}$ \\
\hline
\end{tabular}

Inf. Inf., Londrina, v. 25, n. 4, p. 117 - 141, out./dez. 2020. 


\begin{tabular}{|c|c|c|}
\hline & $\begin{array}{l}\text { indicadores e outras informações, através de } \\
\text { análises de dados do IBGE, dados do CNPq e } \\
\text { outros levantamentos. Aborda também aspectos } \\
\text { do uso e do aprendizado das TICs, assim como } \\
\text { da atividade de pesquisa em TIC. }\end{array}$ & $\begin{array}{l}\text { "canais", "acesso" e } \\
\text { "fontes". }\end{array}$ \\
\hline $\begin{array}{l}\text { Teoria, } \\
\text { Epistemologia e } \\
\text { Interdisciplinaridade } \\
\text { da Ciência da } \\
\text { Informação }\end{array}$ & $\begin{array}{l}\text { Este grupo de pesquisa pretende: } 1 \text {. Contribuir } \\
\text { para a consolidação do campo científico da } \\
\text { Ciência da Informação; } 2 \text {. Favorecer e } \\
\text { aprofundar as relaçóes interdisciplinares, } \\
\text { sobretudo com as áreas de Comunicação, } \\
\text { Ciência da Computação, Epistemologia, } \\
\text { Ciências do Conhecimento, Biblioteconomia, } \\
\text { Museologia, Arquivologia, entre outras, ao } \\
\text { mesmo tempo que mantendo relações } \\
\text { permanentes com todos os outros campos do } \\
\text { conhecimento que formam de uma ou outra } \\
\text { maneira, seu domínio de referência ou } \\
\text { aplicação; 3. Reconstruir, modelar, avaliar as } \\
\text { novas configurações epistêmicas } \\
\text { contemporâneas interdisciplinares, } \\
\text { transdisciplinares. }\end{array}$ & $\begin{array}{l}\text { "ciência", "brasil”, } \\
\text { "transferência”, } \\
\text { "organização", "uso", } \\
\text { "sistema”, } \\
\text { "conhecimento", } \\
\text { "digital”, } \\
\text { "comunicação", "social”, } \\
\text { "análise”, "cientifica”, } \\
\text { "tecnologia", "web", } \\
\text { "documental", } \\
\text { "bibliografias", } \\
\text { "publicações" e } \\
\text { "fontes". }\end{array}$ \\
\hline
\end{tabular}

Fonte: criação dos autores com base no PPGCI IBICT/UFRJ 2020

O resultado das análises do IRaMuTeQ demonstrou que existe uma correlação semântica entre os termos retirados das teses e dissertações com as linhas de pesquisa, as áreas de interesse dos docentes e temas dos grupos de pesquisa. Assim, pode-se inferir que existe um conjunto de termos comuns trabalhados organicamente no campo da Ciência da Informação.

\section{CONCLUSÃO}

A Ciência da Informação trata de questões voltadas para geração, comunicação, reprodução e apropriação do conhecimento, abrangendo diferentes perspectivas sobre o fenômeno da informação. Seu objeto de estudo "informação" é um recurso comum a todas as áreas do conhecimento e, por isso, é considerada uma ciência de natureza interdisciplinar sobretudo pelos seus métodos, técnicas de coleta, tratamento e recuperação da informação.

O resultado da análise dos títulos e resumos das teses e dissertações através do programa IRaMuTeQ apontou para um grupo de temas centrais (guarda-chuva) que possuem ramificações composto por: usos e efeitos da informação; metrias da informação; estudos sobre instituições sediadas no Rio de Janeiro; perspectivas teóricas e conceituais na Ciência da Informação.Nesse 
sentido, o estudo empírico revelou as principais abordagens das pesquisas acadêmicas desenvolvidas durante os 50 anos do PPGCl.

Nesse limiar, a pesquisa espera contribuir para o conhecimento histórico da Ciência da Informação no Brasil.

\section{REFERÊNCIAS}

ARAUJO, Carlos A. A. O que é ciência da informação. Editora: KMA, 2018.

BARRETO, Aldo. Uma história da Ciência da Informação in: Para entender a Ciência da Informação org. Lídia Maria B. B. Toutain. Salvador, EDUFBA, 2007.

BORKO, Harold. Information science: what is it? American Documentation, v.19, n.1, p. 3-5, 1968.

CAMARGO, Brigido V.; JUSTO, Ana Maria. IRAMUTEQ: um software gratuito para análise de dados textuais. Associação Brasileira de Psicologia, v. 21, n. 2, p. 513-518, 2013.

CARVALHO, Abigail de O. Pós-graduação em Biblioteconomia e Ciência da Informação: reflexões, sugestões, experiências. Revista da Escola de Biblioteconomia da UFMG, v. 7, n.2, p. 289-309, 1978.

EYRE, John. Some views on the development of professional library education in Brazil. Ciência da Informação-vol. 24, número 1, 1995.

GOFFMAN, William. Information science: discipline or disappearance. ASLIB Proceedings, v. 22 n.12, p.589-596, 1970.

GOMES, Hagar E. Experiência do IBBD em programas de pós-graduação. Revista da Escola de Biblioteconomiada UFMG, v. 3, n.1, p.13-26, 1974.

IBBD. Quem é quem na biblioteconomia e documentação no Brasil. Rio de Janeiro: IBBD, 1970.

MARCHAND, Pascal; RATINAUD, Pierre. L' analyse de similitude appliqué aux corpus textueles: les primaires socialistes por l' election présidentielle française. In: In Actes des 11eme Journées internation-alesd' Analyse statistique des Données Textuelles. JADT, pp. 687- 699, 2012.

MARTELETO, Regina M. A pesquisa em Ciência da Informação no Brasil: marcos institucionais, cenários e perspectivas. Perspect. ciênc. inf., Belo Horizonte, v. 14, n. spe, p.19-40, 2009 
PINHEIRO, Lena V. R.; LOUREIRO, José M. M. Traçados e limites da Ciência da Informação. Ciência da Informação, Brasília, v.24, n.1, p.42-53, jan./jul.1995.

PINHEIRO, Lena V. Ri. Cenário da pós-graduação em Ciência da Informação no Brasil, influências e tendências In: Encontro Nacional de Pesquisa em Ciência da Informação, 8.: 2007, Salvador. Anais [...]. Salvador: UFBA, p.14, 2007.

SACERDOTE, Helena C. de S. A mediação segundo Feuerstein e o uso da informação em educação on-line. 2018. 229 f. Tese. (Doutorado em Ciência da Informação). Faculdade de Ciência da Informação, Universidade de Brasília, 2018.

SARACEVIC, Tefko. Ciência da informação: origem, evolução e relações.

Perspect. ciênc. inf., Belo Horizonte, v. 1, n. 1, p. 41-62, jan./jun. 1996.

SOUZA, Rosali F. de; STUMPF, Ida R. C. Ciência da Informação como área do conhecimento: abordagem no contexto da pesquisa e da pós-graduação no Brasil. Perspect. ciênc. inf., Belo Horizonte, v. 14, n. spe, p. 41-58, 2009.

SOUZA, Terezinha B. de.; RIBEIRO, Fernanda. Os cursos de Ciência da Informação no Brasil e em Portugal: perspectivas diacrônicas. Inf. Inf., Londrina, v. 14, n. 1, p. 82 - 102, jan./jun. 2009.

\title{
50 YEARS OF PPGCI IBICT: TEXTUAL ANALYSIS OF THE SCIENTIFIC PRODUCTION THROUGH IRAMUTEQ
}

\begin{abstract}
Introduction: Textual analysis of the scientific production of the 50 years of the Graduate Program in Information Science of the Brazilian Institute of Information in Science and Technology. Objective: To identify the themes worked on in academic research carried out in the postgraduate program during its 50 years, due to its representativeness as the first master's course in Information Science in Brazil. Methodology: Empirical research based on the collection of data from dissertations and theses, in institutional repertoires (CAPES, BDTD, RIDI, Pantheon and RIUFF), for textual analysis through the IRaMuTeQ program and discussion based on the bibliographic and documentary review. Results: 750 titles and 454 abstracts from (167) thesis and dissertations (583) were analyzed, which presented the main thematic approaches: uses and effects of information; metrics of information; studies on institutions based in Rio de Janeiro; theoretical and conceptual perspectives in Information Science. Conclusions: The study hopes to contribute to the historical knowledge of Information Science in Brazil.
\end{abstract}

Descriptors:Information Science. Scientific production. Postgraduate. Ibict. IraMuTeQ.

\section{AÑOS DE PPGCI IBICT: ANÁLISIS TEXTUAL DE LA PRODUCCIÓN CIENTÍFICA A TRAVÉS DE IRAMUTEQ}




\section{RESUMEN}

Introducción: Análisis textual de la producción científica de los 50 años del Programa de Posgrado en Ciencias de la Información del Instituto Brasileño de Información en Ciencia y Tecnología. Objetivo: identificar los temas trabajados en la investigación académica realizada en el programa de posgrado durante sus 50 años, debido a su representatividad como el primer curso de maestría en Ciencias de la Información en Brasil. Metodología: Investigación empírica basada en la recopilación de datos de disertaciones y tesis, en repertorios institucionales (CAPES, BDTD, RIDI, Pantheon y RIUFF), para análisis textuales a través del programa IRaMuTeQ y discusión basada en la revisión bibliográfica y documental. Resultados: 750 títulos y 454 resúmenes de tesis (167) y disertaciones (583) se analizaron, que presentaron los principales enfoques temáticos: usos y efectos de la información; métricas de información; estudios sobre instituciones con sede en Río de Janeiro; perspectivas teóricas y conceptuales en ciencias de la información. Conclusiones: El estudio espera contribuir al conocimiento histórico de la Ciencia de la Información en Brasil.

Descriptores: Ciencias de la Información. Producción científica. Postgrado. Ibict, IRaMuTeQ.

Recebido em: 10.08 .2020

Aceito em: 21.11.2020 